\title{
Pembelajaran Dengan Pendekatan Sainitifik Dalam Mata Pelajaran Pendidikan Agama Kristen di Kelas XII SMK Nusantara Palu
}

\author{
Christofer Wauran Bone* ${ }^{* 1}$, Freliyanti², \\ Sekolah Tinggi Teologi Bala Keselamatan Palu \\ *fresh_yanti@yahoo.com
}

\begin{abstract}
They are learning against the scientific studies Christianity in class XI SMK Nusantara Palu, a lack of the institution of a school or teacher Christianity in developing learning the rendering in 2013. curriculum. The research was to see how the school or teacher Christianity uses creative learning the rendering in a lesson. Christian religious education Quantitative is the method used for the data process associated with Statistics. Data processing was using manual calculations based on the survey research distributed and occupied by students. Learning by a scientific approach to heed the Christian religion is very necessary and can help the teacher involve students in the process of learning activities. There should have been motivated to increase student learning activities and improve student learning activities. Motivated teachers who had children by passion and enterprising in learning. The results of the study in the article that a student expresses the teaching process become active in education Christianity and Christian education teachers be motivated to creative.
\end{abstract}

Keywords: learning scientific approach. christian religious education

\begin{abstract}
Abstrak: Pembelajaran dengan pendekatan saintifik terhadap mata pelajaran pendidikan agama Kristen di kelas XI SMK Nusantara Palu, Pada setiap kegiatan proses pembelajaran selain diterapkannya pendekatan saintifik seorang guru harus mampu menetapkan model pembelajaran yang sesuai dengan materi yang akan diberikan kepada siswa masih membangun keaktifan siswa untuk mulai bertanya atau untuk berpikir secara kreatif tetapi kenyataannya masih kurangnya lembaga sekolah atau guru agama Kristen dalam mengembangkan atau menerapkan pembelajaran dengan pendekatan saintifik yang ada di dalam kurikulum 2013. Penelitian ini dilakukan dengan tujuan untuk mengetahui bagaimana lembaga sekolah atau guru agama kristen dalam memberikan pembelajaran yang kreatif dalam hal ini menggunakan pembelajaran dengan pendekatan saintifik dalam pelajaran Pendidikan Agama Kristen. kuantitatif adalah metode yang dipakai karena data yang diolah berhubungan dengan statistik. Pengolahan data dilakukan berdasarkan angket penelitian yang di bagikan dan di isi oleh siswa. pembelajaran dengan pendekatan saintifik terhadap pelajaran agama kristen sangat perlu dan dapat membantu peserta didik dalam membuat keterlibatan siswa dalam proses pembelajaran agar aktif. Maka untuk meningkatkan aktivitas belajar anak, perlu adanya motivasi-motivasi guru yang sekiranya anak-anak menjadi semangat dan giat dalam belajar. Hasil kajian dalam artikel ini mengungkapkan bahwa siswa menjadi aktif dalam proses pembelajaran Pendidikan Agama Kristen.
\end{abstract}

Kata Kunci: Pembelajaran, Pendekatan saintifik dan Pendidikan Agama Kristen.

\begin{tabular}{llll}
\hline Article History : & Received: 28-08-2021 & Revised: 06-12-2021 & Accepted: 27-12-2021
\end{tabular}




\section{Pendahuluan}

Tingkat kemampuan dan upaya yang dikembangkan oleh manusia dalam mengatasi masalah tantangan dan hambatan sangat dipengaruhi oleh pengetahuan, pemahaman, kesadaran dan ketrampilan yang dimiliki oleh diri setiap orang. Dalam upaya menjawab tantangan tersebut di atas, maka perkembangan sumber daya diprioritaskan. Perkembangan sumber daya yang diprioritaskan adalah sumber daya manusia. Salah satu upaya yang dilakukan agar sumber daya manusia meningkat adalah melalui pendidikan. ${ }^{1}$

Pendidikan Agama Kristen merupakan pendidikan yang mendasarkan diri pada Alkitab sebagai firman Allah dan menjadikan Kristus sebagai pusat beritanya dan bermuara pada hasilnya, yaitu mendewasakan murid, firman Tuhan yang berkaitan dengan tugas dan tanggungjawab seorang guru dalam melaksanakan pendidikan agama, untuk menghadirkan nilai-nilai Kristiani dilingkungan sekolah, dilihat dalam surat Rasul Paulus kepada Timotius yang mengatakan bahwa "Segala tulisan yang diilhamkan Allah memang bermanfaat untuk mengajar, untuk menyatakan kesalahan, untuk memperbaiki kelakuan dan untuk mendidik orang dalam kebenaran" (2 Timotius 3: 16). ${ }^{2}$

Pengajaran PAK bagi siswa disekolah bertujuan untuk menuntun anak agar mengenal Yesus Kristus sebagai Tuhan dan Juru selamat. Memperoleh pengenalan yang benar tentang Allah melalui persekutuan yang sesungguhnya akan memungkinkan anak berada dalam persekutuan damai dengan sesama menuju masa depan yang sejahtera. ${ }^{3}$ Karena begitu penting tujuan pendidikan yang harus di capai siswa, maka pemerintah memikirkan dan menerapkan kurikulum 2013. Kurikulum 2013 adalah sebuah kurikulum yang terintegrasi. Maksud dari integrasi ini adalah sebuah kurikulum yang mengintegrasikan skill, theme, consepts and topic baik dalam bentuk within single disciplines, acrous several disciplines and within and acrous learners.dengan kata lain bahwa kurikulum 2013 ialah kurikulum yang terpadu sebagai suatu konsep dapat di katakan sebagai sebuah sistem atau pendekatan pembelajaran yang melibatkan beberapa di siplin ilmu untuk memberikan pengalaman yang bermakna dan luas terhadap peserta didik dari dua pengertian di atas dapat di simpulkan bahwa pendekatan saintifik atau ilmiah adalah suatu teknik pembelajaran yang menempatkan

\footnotetext{
${ }^{1}$ Dien Sumiyatiningsih, Mengajar Dengan Kreatif Dan Menarik (Yogyakarta: Andi, 1987), 3.

2 Lembaga Alkitab Indonesia, 'Alkitab Terjemahan Baru' (Jakarta: Lembaga Alkitab Indonesia, 2017). 5.

${ }^{3}$ Paulus Lilik Kristianto, Prinsip Dan Praktik Pendidikan Agama Kristen (Yogyakarta: Andi, 2006),
} 
siswa menjadi subjek aktif melalui tahapan tahapan ilmiah sehingga mampu mengkonstruk pengetahuan baru atau memadukan dengan pengetahuan sebelumnya. Pendekatan saintifik /atau ilmiah lebih terbukti lebih efektif dalam pembelajaran tradisional. ${ }^{4}$ Adanya peningkatan aktivitas belajar anak maka untuk meningkatkan aktivitas belajar anak, perlu adanya motivasi-motivasi guru yang sekiranya anak-anak menjadi semangat dan giat dalam belajar. ${ }^{5}$

Model Pembelajaran adalah kerangka konseptual yang melukiskan prosedur yang sistematis dalam mengorganisasikan pengalaman belajar untuk mencapai tujuan belajar tertentu dan berfungsi sebagai pedoman bagi para pengajar dalam merencanakan aktivitas belajar mengajar. ${ }^{6}$ Siswa diharapkan lebih aktif dalam pembelajaran, serta memahami pelajaran yang sedang diajarkan untuk memperoleh pengetahuan.

Model pembelajaran yang sesuai dengan isi dalam permen dikbud nomor 103 Tahun 2014 dan permen dibud nomor 22 Tahun 2016 adalah model pembelajaran yang bukan berbasis ceramah atau hafalan, tetapi model pembelajaran yang berbasis aktivitas dan kreativitas, menginspirasi, menyenangkan dan berprakarsa, serta lebih mengacu pada makna alami, sesuai fitrah manusia' yaitu: terpusat pada peserta didik, autentik, kontekstual, dan bermakna bagi kehidupan peserta didik sehari-hari. Model pembelajaran yang dimaksud, misalnya discovery learning, project-based learning, problem-based learning, dan inquiry learning.Riadi menuliskan pengertian, prinsip dan langkah pendekatan saintifik adalah pendekatan saintifik (scientific approach) adalah model pembelajaran yang menggunakan kaidah-kaidah keilmuan yang memuat serangkaian aktivitas pengumpulan data melalui observasi, menanya, eksperimen, mengolah informasi atau data, kemudian mengkomunikasikan. ${ }^{7}$ Penerapan pendekatan saintifik dalam pembelajaran melibatkan keterampilan proses seperti mengamati, mengklafikasi, mengukur, meramalkan, menjelaskan, dan menyimpulkan. Hal tersebut sejalan dengan pemikiran kemendikbud melalui materi diklat guru implementasi Kurikulum 2013.

Dengan menerapkan pendekatan pembelajaran saintifik dalam proses pembelajaran Pendidikan Agama Kristen diharapkan tujuan dari pembelajaran tersebut tercapai dan proses yang ada dapat berjalan dengan menyenangkan. Seperti apa yang dikatakan Tilaar (2012) bahwa pembentukan karakter dapat di lakukan melalui

\footnotetext{
${ }^{4}$ https://www.kemdikbud.go.id, 'Paparan Wamendik' (Jakarta: https://www.kemdikbud.go.id). 2008), 132

${ }^{5}$ Syah.Muhibin, Psikologi Pendidikan Dengan Pendekatan Baru (Bandung: Remaja Rosda Karya,

${ }^{6}$ Ahmad rohani, Pengelolaan Pengajaran (Jakarta: PT Bumi Aksara, 2004), 120,

${ }^{7}$ Muchlisin Riadi, 'Prinsip Dan Langkah Pendekatan Saintifik' (Jakarta: Kajian Pustaka.Com, 2019).
} 
rekayasa lingkungan beberapa strategi, (1) keteladanan, (2) interfensi, (3) pembiasaan yang dilakukan secara konsisten, dan (4) penguatan. ${ }^{8}$ Hal tersebut pula diharapkan dalam proses pembelajaran Pendidikan Agama Kristen.Stott mengemukakan Bahwa Pendidikan Agama Kristen menutun pembacanya pada iman dan keselamatan di dalam Yesus Kristus, Alkitab juga terbukti telah membentuk, menopang, mengarahkan dan memperbaharui, serta mempersatukan dan menyegarkan kehidupan pengikutnya. ${ }^{9}$ Maka pembelajaran dengan menggunakan metode pendekatan saintifik sangat membantu terjadinya interaksi antara guru dan siswa.

Dalam interaksi kegiatan pembelajaran di kelas, guru mempunyai peranan yang sangat penting. Ia harus berusaha secara terus-menerus membantu peserta didik menggali dan mengembangkan potensinya. Salah satu cara guru membantu peserta didik adalah dengan memilih dan menentukan strategi pembelajaran yang tepat untuk mencapai tujuan pembelajaran. ${ }^{10}$ Kurikulum yang berpusat pada siswa (student centered) yang mengharuskan siswa untuk aktif dengan pendekatan saintifik.

Dalam proses pembelajaran, guru dan siswa merupakan dua komponen yang tidak bisa dipisahkan. Antara dua komponen tersebut harus terjalin interaksi yang saling menunjang agar hasil belajar siswa dapat tercapai secara optimal.

Pembelajaran dapat diartikan sebagai "segala usaha atau proses belajar mengajar dalam rangka terciptanya proses belajar mengajar yang efektif dan efisien". 11Pembelajaran dapat didefinisikan sebagai suatu proses yang mana suatu kegiatan berasal atau berubah lewat reaksi suatu situasi yang dihadapi dan karakteristikkarakteristik dari perubahan aktivitas tersebut tidak dapat dijelaskan berdasarkan kecenderungan-kecenderungan reaksi asli, kematangan atau perubahan-perubahan sementara. ${ }^{12}$

Peranan pendekatan saintifik perlu diterapkan di SMK Nusantara Palu khususnya kelas XI farmasi. Artikel ini ditulis untuk mengetahui rumusan masalah yaitu; apa yang di maksud pembelajaran dengan pendekatan saintifik, dan mengetahui bagaimana mengajar Pendidikan Agama Kristen menggunakan pembelajaran dengan pendekatan saintifik yang efektif, pada siswa kelas XI Farmasi SMK Nusantara Palu

\footnotetext{
${ }^{8}$ Amir Hamzah, Etos Kerja Guru (Jakarta: Literasi Nusantara, 2019).

${ }^{9}$ B.S Sidjabat, Mengajara Secara Profesional (Jakarta: BPK Gunung Mulia), 13.

${ }^{10}$ Khanifatul, Pembelajaran Inovatif.124.

${ }^{11}$ https://www.asikbelajar.com, 'Pengertian Proses Pembelajaran' (https://www.asikbelajar.com, 2020).

${ }^{12}$ B.S Sidjabat, Mengajar Secara Profesional (Jakarta: BPK Gunung Mulia), 35.
} 


\section{Metode Penelitian}

Penelitian ini menggunakan metode kualitatif untuk menjelaskan suatu fenomena dengan sedalam-dalamnya dengan cara pengumpulan data yang sedalam-dalamnya pula, yang menunjukkan pentingnya kedalaman dan detail suatu data yang diteliti untuk menganalisis kejadian, fenomena, atau keadaan secara sosial. Penulis membuat prosedur penelitian terarah untuk mencapai tujuan yang diinginkan, yaitu untuk mendapatkan data-data yang akurat dan dapat menunjang penulisan ini. Selanjutnya analisis data dilakukan dengan memaparkan obyek yang diteliti lalu disajikan dalam bentuk uraian narasi.

\section{Hasil dan Pembahasan}

\section{Pendidikan dalam Alkitab}

Pendidikan Agama Kristen dalam Alkitab merupakan dasar alkitabiah yang perlu dijabarkan dan dikembangkan menjadi pusat proses pendidikan yang berlandaskan pada Alkitab. Melalui Pendidikan Agama Kristen peserta didik mengalami perjumpaan dengan Allah yang dikenal, dipercaya dan diimaninya. Stott mengemukakan bahwa Pendidikan Agama Kristen menutun pembacanya pada iman dan keselamatan di dalam Yesus Kristus, Alkitab juga terbukti telah membentuk, menopang, mengarahkan, memperbaharui, dan mempersatukan serta menyegarkan kehidupan pengikutnya. ${ }^{13}$ Menghasilkan manusia yang mampu menghayati imannya secara bertanggung jawab serta berakhlak mulia

Bagi orang israel, pendidikan rohani, merupakan bagian integral dari perjanijian antara Allah dengan umatnya. (UL.6:4-9), memberikan peraturan peraturan, pengajaran di berikan Allah kepada bangsa Israel dengan maksud agar umatnya memahami kehendak Allah dalam kehidupanya sehingga setiap umat Allah dari semua golongan umur dapat saling mengasihi terutama kepada Allah sebagai pencipta. Pelaksanaan PAK mendapat penekanan yang kuat. Pertama menyangkut perhatian terhadap pendidikan dan pengajaran bagi anak-anak sebagaimana dikatakan dalam Markus 10:13-16 di mana Yesus menegaskan bahwa anak-anak memiliki hak penuh atas kehidupan di dalam Kerajaan Allah

\section{Guru Pendidikan Agama Kristen}

Yesus adalah guru Agung yang pengajara-Nnya luar biasa (Markus 1:22), Dia adalah Pendidik yang tiada taranya (Ayub 36:22). Guru adalah pendidik profesional menurut

13 B.S Sidjabat, Mengajara Secara Profesional, 35. 
Undang-Undang RI Ni). 14, Bab I Pasal 1 ayat 1, yang memiliki tugas utama mendidik, mengajar, membimbing, mengarahkan, melatih, menilai dan mengevaluasi peserta didik. ${ }^{14}$ Guru harus memiliki kualifikasi sesuai standar. guru pendidikan agama kristen adalah seorang yang membantu peserta didik berkembang untuk dapat memasuki persekutuan iman dengan Tuhan yesus sehingga menjadi pribadi yang bertanggung jawab baik kepada Allah maupun kepada manusia. ${ }^{15}$ Guru Pendidikan Agama Kristen, merancang pembelajaran secara menarik dalam proses belajar mengajar. Karena guru PAK tugas dan perannya lebih dari sekedar mengajar atau mengalihkan ilmu, tetapi turut ambil andil dalam pembentukan karakter juga menjadi panggilan pelayanan Kerajaan Surga untuk keselamatan

\section{Pendekatan Seintifik}

Pendekatan pembelajaran saintifik sangat perlu dalam proses pembelajaran agama kristen agar pengajaran dan pengetahuan yang berdasarkan Alkitab itu yang di bagikan oleh guru dapat di mengerti dan di pahami oleh siswa. ${ }^{16}$ Dengan menggunakan pendekatan saintifik membuat siswa dapat mudah memahami ketika belajar Pendidikan Agama Kristen, indikasi keberhasilan ketika proses pembelajaran dengan pendekatan saintifik perlahan di aplikasikan dengan baik di SMK Nusantara Palu dapat di lihat dari cara belajar siswa yang semakin aktif, mereka begitu antusias menangkap pelajaran yang ada, memberikan ide-ide dalam diskusi, melakukan brain storming (curah pendapat) dengan percaya diri. Dengan sistem yang sistematik ini, yakni mengamati, menanya, mengumpulkan informasi, membuat kesimpulan, dan mengkomunikasikan tujuan pembelajaran dapat tercapai dalam hal ini khususnya kompetensi inti dasar dan kompetensi inti Pendidikan Agama Kristen.

Pendekatan seintifik menjadikan pembelajaran lebih aktif dan tidak membosankan, siswa dapat mengonstruksi pengetahuan dan keterampilannya melalui fakta-fakta yang ditemukan dalam penyelidikan di lapangan guna pembelajaran. Manfaat pembelajaran dengan metode pendekatan saintifik di kelas XI Farmasi SMK Nusantara Palu, siswa dapat merasakan belajar bukan lagi sebuah beban melainkan sebuah kebutuhan, dengan demikian minat belajar semakin meningkat, hasilnya dapat di lihat dalam tabel-tabel, berikut;

\footnotetext{
14 Dept Pendidikan \& Kebudayaan, Guru Dan Dosen (Jakarta: Himpunan UU RI, 2009), 10.

15 Tim Penyusun Kamus Besar Bahasa Indonesia, Kamus Besar Bahasa Indonesia (Jakarta: Balai Pustaka, 1995).751.

16 https://www.kemdikbud.go.id.
} 
Tabel $4.6 \mathrm{~N}=20$

Pembelajaran Saintifik Membuat Saya Berani Tampil Dalam Presentase di Kelas

\begin{tabular}{|l|l|l|l|}
\hline \multicolumn{1}{|c|}{ Valid } & \multicolumn{1}{|c|}{$\begin{array}{c}\text { Jawaban/ } \\
\text { Frekwensi }\end{array}$} & Persentase & Total \\
\hline Setuju (S) & 19 & $19: 20 \times 100=90 \%$ & \\
\hline Tidak Setuju (TS) & & & \\
\hline $\begin{array}{l}\text { Ragu Dan Tidak Ada } \\
\text { Pendapat }\end{array}$ & 1 & $1: 20 \times 100=10 \%$ & \\
\hline
\end{tabular}

Berdasarkan tabel di atas dapat disimpulkan bahwa responden 19 (90\%) setuju dan 1 (10\%)responden ragu-ragu dan tidak ada pendapat.

Tabel $4.7 \mathrm{~N}=20$

Dengan Pendekatan Saintifik Dalam Pembelajaran PAK, Saya Menjadi Bersemangat

\begin{tabular}{|l|l|c|c|}
\hline \multicolumn{1}{|c|}{ Valid } & $\begin{array}{c}\text { Jawaban/ } \\
\text { Frekwensi }\end{array}$ & Persentase & Total \\
\hline \hline Setuju (S) & 20 orang & $20: 20 \times 100=100 \%$ & \\
\hline Tidak Setuju (TS) & & & \\
\hline $\begin{array}{l}\text { Ragu Dan Tidak Ada } \\
\text { Pendapat }\end{array}$ & & & \\
\hline
\end{tabular}

Berdasarkan tabel responden sebanyak 20 orang (100\%) setuju, ketika dalam pembelajaran PAK menggunakan pendekatan saintifik siswa menjadi semangat.

Tabel $4.8 \mathrm{~N}+20$

Saya Cukup Memahami Ketika Di Berikan Tugas Makalah Oleh Guru Saya Dan Mampu Mengerjakanya

\begin{tabular}{|l|l|l|l|}
\hline \multicolumn{1}{|c|}{ Valid } & \multicolumn{1}{|c|}{$\begin{array}{c}\text { Jawaban/ } \\
\text { Frekwensi }\end{array}$} & \multicolumn{1}{|c|}{ Persentase } & Total \\
\hline Setuju (S) & 19 & $20: 20 \times 100=100 \%$ & \\
\hline Tidak Setuju (TS) & & $1: 20 \times 10=10 \%$ & \\
\hline $\begin{array}{l}\text { Ragu Dan Tidak Ada } \\
\text { Pendapat }\end{array}$ & 1 & & \\
\hline
\end{tabular}

Berdasarkan tabel responden sebanyak 20 orang (90\%) setuju dan (10\%) raguragu dan tidak ada pendapat, siswa dapat memahami ketika guru memberikan tugas serta mampu mengerjakanya. 
Tabel $4.9 \mathrm{~N}=20$

Pembelajaran Menggunakan Pendekatan Saintifik Membuat Saya Bisa Menarik Kesimpulan Sendiri Tentang Makna Materi PAK Yang Dijelaskan Oleh Guru

\begin{tabular}{|l|l|l|l|}
\hline \multicolumn{1}{|c|}{ Valid } & \multicolumn{1}{|c|}{$\begin{array}{c}\text { Jawaban/ } \\
\text { Frekwensi }\end{array}$} & \multicolumn{1}{c|}{ Persentase } & Total \\
\hline \hline Setuju (S) & 18 & $18: 20 \times 100=80 \%$ & \\
\hline Tidak Setuju (TS) & & & \\
\hline $\begin{array}{l}\text { Ragu Dan Tidak Ada } \\
\text { Pendapat }\end{array}$ & 2 & $2: 20 \times 100=20 \%$ & \\
\hline
\end{tabular}

Berdasarkan tabel responden sebanyak 20 orang, 18 (80\%) setuju 2 (20\%) raguragu dan tidak ada pendapat, ketika pembelajaran menggunakan pendekatan saintifik dapat membuat siswa bisa menarik kesimpulan sendiri tentang makna materi PAK yang di jelaskan oleh guru.

Tabel $4.10 \mathrm{~N}=20$

Saya Suka Dalam Pembelajaran PAK Menggunakan Metode Diskusi

\begin{tabular}{|l|l|l|l|}
\hline \multicolumn{1}{|c|}{ Valid } & \multicolumn{1}{|c|}{$\begin{array}{c}\text { Jawaban/ } \\
\text { Frekwensi }\end{array}$} & Persentase & Total \\
\hline \hline Setuju (S) & 20 & $20: 20 \times 100=100 \%$ & \\
\hline Tidak Setuju (TS) & & & \\
\hline $\begin{array}{l}\text { Ragu Dan Tidak Ada } \\
\text { Pendapat }\end{array}$ & & & \\
\hline
\end{tabular}

Berdasarkan Tabel tersebut dapat di simpulkan bahwa responden sebanyak 20 orang $(100 \%)$ setuju, ketika siswa menyukai dalam pembelajaran PAK menggunakan metode diskusi.

Tabel $4.11 \mathrm{~N}=20$

Saya Tidak Mengantuk Ketika Proses Pelajaran Berlangsung

\begin{tabular}{|l|l|l|l|}
\hline \multicolumn{1}{|c|}{ Valid } & $\begin{array}{c}\text { Jawaban/ } \\
\text { Frekwensi }\end{array}$ & Persentase & Total \\
\hline Setuju (S) & 20 & $20: 20 \times 100=100 \%$ & \\
\hline Tidak Setuju (TS) & & & \\
\hline $\begin{array}{l}\text { Ragu Dan Tidak Ada } \\
\text { Pendapat }\end{array}$ & & & \\
\hline
\end{tabular}


Berdasarkan tabel menunjukkan bahwa responden sebanyak 20 orang (100\%) setuju, ketika dalam proses pembelajaran berlangsung mereka tidak mengantuk.

Tabel $4.12 \mathrm{~N}=20$

Saya Merasa Tidak Bosan Dalam Pembelajaran PAK Menggunakan Pendekatan Saintifik

\begin{tabular}{|l|l|l|l|}
\hline \multicolumn{1}{|c|}{ Valid } & $\begin{array}{c}\text { Jawaban/ } \\
\text { Frekwensi }\end{array}$ & Persentase & Total \\
\hline Setuju (S) & 20 & $20: 20 \times 100=100 \%$ & \\
\hline Tidak Setuju (TS) & & & \\
\hline $\begin{array}{l}\text { Ragu Dan Tidak Ada } \\
\text { Pendapat }\end{array}$ & & & \\
\hline
\end{tabular}

Berdasarkan tabel tersebut dapat di simpulkan bahwa responden sebanyak 20 orang $(100 \%)$ setuju ketika siswa dalam pembelajaran PAK menggunakan pendekatan saintifik tidak merasakan bosan.

Tabel $4.13 \mathrm{~N}=20$

Saya Suka Jika Guru Memberikan Tugas Yang di Kerjakan Dengan Kelompok di Kelas

\begin{tabular}{|l|l|l|l|}
\hline \multicolumn{1}{|c|}{ Valid } & $\begin{array}{c}\text { Jawaban/ } \\
\text { Frekwensi }\end{array}$ & Persentase & Total \\
\hline Setuju (S) & 20 & $20: 20 \times 100=100 \%$ & \\
\hline Tidak Setuju (TS) & & & \\
\hline $\begin{array}{l}\text { Ragu Dan Tidak Ada } \\
\text { Pendapat }\end{array}$ & & & \\
\hline
\end{tabular}

Berdasarkan tabel tersebut sebanyak 20 responden (100\%) setuju, ketika guru memberikan tugas yang di kerjakan membentuk kelompok dengan teman di kelas.

Tabel $4.14 \mathrm{~N}=20$

Saya Suka Mengantuk Dalam Proses Pembelajaran

\begin{tabular}{|l|l|l|l|}
\hline \multicolumn{1}{|c|}{ Valid } & $\begin{array}{c}\text { Jawaban/ } \\
\text { Frekwensi }\end{array}$ & \multicolumn{1}{c|}{ Persentase } & Total \\
\hline Setuju (S) & & & \\
\hline Tidak Setuju (TS) & 20 & $20: 20 \times 100=100 \%$ & \\
\hline $\begin{array}{l}\text { Ragu Dan Tidak Ada } \\
\text { Pendapat }\end{array}$ & & & \\
\hline
\end{tabular}

Berdasarkan Tabel reponden sebanyak 20 orang (100\%) tidak setuju, ketika dalam proses pembelajaran mereka suka mengantuk. 
Tabel $4.15 \mathrm{~N}=20$

Saya Suka Menganggu Teman Saat Jam Pembelajaran PAK

\begin{tabular}{|l|l|l|l|}
\hline \multicolumn{1}{|c|}{ Valid } & \multicolumn{1}{|c|}{$\begin{array}{c}\text { Jawaban/ } \\
\text { Frekwensi }\end{array}$} & \multicolumn{1}{c|}{ Persentase } & Total \\
\hline Setuju (S) & & & \\
\hline Tidak Setuju (TS) & 20 & $20: 20 \times 100=100 \%$ & \\
\hline $\begin{array}{l}\text { Ragu Dan Tidak Ada } \\
\text { Pendapat }\end{array}$ & & & \\
\hline
\end{tabular}

Berdasarkan tabel sebanyak 20 responden (100\%) tidak setuju, dalam pembelajaran PAK suka menganggu sesama teman kelas mereka.

Tabel $4.16 \mathrm{~N}=20$

Saya Merasa Ada Perubahan Karakter Saya Ketika Selesai Pembelajaran pendidikan Agama Kristen

\begin{tabular}{|l|l|l|l|}
\hline \multicolumn{1}{|c|}{ Valid } & $\begin{array}{c}\text { Jawaban/ } \\
\text { Frekwensi }\end{array}$ & Persentase & Total \\
\hline \hline Setuju (S) & 20 & $20: 20 \times 100=100 \%$ & \\
\hline Tidak Setuju (TS) & & & \\
\hline $\begin{array}{l}\text { Ragu Dan Tidak Ada } \\
\text { Pendapat }\end{array}$ & & & \\
\hline
\end{tabular}

Berdasarkan tabel menyatakan bahwa responden sebanyak 20 orang (100\%) setuju, siswa merasakan perubahan karakter ketika selesai pembelajaran PAK.

Tabel $4.17 \mathrm{~N}=20$

Saya semangat Ketika Jam Pembelajaran Agama Kristen Tiba

\begin{tabular}{|l|l|l|l|}
\hline \multicolumn{1}{|c|}{ Valid } & $\begin{array}{c}\text { Jawaban/ } \\
\text { Frekwensi }\end{array}$ & Persentase & Total \\
\hline Setuju (S) & 20 & $20: 20 \times 100=100 \%$ & \\
\hline Tidak Setuju (TS) & & & \\
\hline $\begin{array}{l}\text { Ragu Dan Tidak Ada } \\
\text { Pendapat }\end{array}$ & & & \\
\hline
\end{tabular}

Berdasarkan tabel tersebut dapat di simpulkan bahwa responden sebanyak 20 orang (100\%) siswa merasa bersemangat ketika jam pembelajaran Agama Kristen. 
Tabel $4.18 \mathrm{~N}=20$

Guru Pendidikan Agama Kristen Memberikan Contoh dan Teladan Dalam Kehidupanya Sehari Hari

\begin{tabular}{|l|c|c|c|}
\hline \multicolumn{1}{|c|}{ Valid } & $\begin{array}{c}\text { Jawaban/ } \\
\text { Frekwensi }\end{array}$ & Persentase & Total \\
\hline Setuju (S) & 20 orang & $20: 20 \times 100=100 \%$ & \\
\hline Tidak Setuju (TS) & & & \\
\hline $\begin{array}{l}\text { Ragu Dan Tidak Ada } \\
\text { Pendapat }\end{array}$ & & & \\
\hline
\end{tabular}

Berdasarkan tabel sebanyak 20 responden (100\%) setuju, ketika guru agama kristen mereka dapat memberikan contoh dan teladannya dalam kehidupan sehariharinya.

Tabel $4.19 \mathrm{~N}=20$

Dalam Pembelajaran PAK Guru Mewajibkan Membawa Alkitab dan membaca Bersamasama

\begin{tabular}{|l|l|l|l|}
\hline \multicolumn{1}{|c|}{ Valid } & \multicolumn{1}{c|}{$\begin{array}{c}\text { Jawaban/ } \\
\text { Frekwensi }\end{array}$} & Persentase & Total \\
\hline Setuju (S) & 20 & $20: 20 \times 100=100 \%$ & \\
\hline Tidak Setuju (TS) & & & \\
\hline $\begin{array}{l}\text { Ragu Dan Tidak Ada } \\
\text { Pendapat }\end{array}$ & & & \\
\hline
\end{tabular}

Berdasarkan tabel tersebut dapat di simpulkan bahwa sebanyak 20 responden (100\%) setuju, ketika dalam pembelajaran PAK guru mewajibkan siswa membawa Alkitab dan membacanya bersama.

Tabel $4.20 \mathrm{~N}=20$

Pelajaran Agama Kristen Menjadi Pembelajaran Yang Menyenangkan

\begin{tabular}{|l|l|l|l|}
\hline \multicolumn{1}{|c|}{ Valid } & \multicolumn{1}{|c|}{$\begin{array}{c}\text { Jawaban/ } \\
\text { Frekwensi }\end{array}$} & \multicolumn{1}{c|}{ Persentase } & Total \\
\hline Setuju (S) & 16 & $16: 20 \times 100=60 \%$ & \\
\hline Tidak Setuju (TS) & & $4: 20 \times 100=40 \%$ & 4 \\
\hline $\begin{array}{l}\text { Ragu Dan Tidak Ada } \\
\text { Pendapat }\end{array}$ & 4 & & \\
\hline
\end{tabular}

Berdasarkan tabel tersebut dapat di simpulkan bahwa, responden sebanyak $60 \%$ atau 16 orang setuju dan $40 \%$ atau 4 responden ragu ragu dan tidak ada pendapat ketika pembelajaran PAK yang lebih menyenangkan di banding pembelajaran yang lainya 
Tabel $4.21 \mathrm{~N}=20$

Guru Agama Kristen Suka Membantu Ketika Ada Pelajaran Yang Saya Kurang Paham

\begin{tabular}{|l|l|l|l|}
\hline \multicolumn{1}{|c|}{ Valid } & \multicolumn{1}{|c|}{$\begin{array}{c}\text { Jawaban/ } \\
\text { Frekwensi }\end{array}$} & Persentase & Total \\
\hline Setuju (S) & 20 & $20: 20 \times 100=100 \%$ & \\
\hline Tidak Setuju (TS) & & & \\
\hline $\begin{array}{l}\text { Ragu Dan Tidak Ada } \\
\text { Pendapat }\end{array}$ & & & \\
\hline
\end{tabular}

Berdasarkan tabel tersebut dapat di simpulkan bahwa sebanyak 20 responden (100\%) setuju ketika guru agama kristen suka membantu siswanya jika ada pembelajaran yang kurang di pahami.

Tabel $4.22 \mathrm{~N}=20$

Guru Agama Kristen Suka Peduli Kepada Saya

\begin{tabular}{|l|l|l|l|}
\hline \multicolumn{1}{|c|}{ Valid } & \multicolumn{1}{|c|}{$\begin{array}{l}\text { Jawaban/ } \\
\text { Frekwensi }\end{array}$} & \multicolumn{1}{|c|}{ Persentase } & Total \\
\hline Setuju (S) & 20 & $\begin{array}{l}20: 20 \times 100= \\
100 \%\end{array}$ & \\
\hline Tidak Setuju (TS) & & & \\
\hline $\begin{array}{l}\text { Ragu Dan Tidak Ada } \\
\text { Pendapat }\end{array}$ & & & \\
\hline
\end{tabular}

Berdasarkan tabel tersebut dapat di simpulkan bahwa sebanyak 20 responden $(100 \%)$ setuju, ketika guru agama kristen suka peduli kepada muridnya.

Tabel $4.23 \mathrm{~N}=20$

Pelajaran Agama Kristen Bisa Membuat Perubahan Dalam Pergaulan Saya

\begin{tabular}{|l|l|l|l|}
\hline \multicolumn{1}{|c|}{ Valid } & \multicolumn{1}{|c|}{$\begin{array}{c}\text { Jawaban/ } \\
\text { Frekwensi }\end{array}$} & \multicolumn{1}{|c|}{ Persentase } & Total \\
\hline \hline Setuju (S) & 20 & $\begin{array}{l}20: 20 \times 100= \\
100 \%\end{array}$ & \\
\hline Tidak Setuju (TS) & & & \\
\hline $\begin{array}{l}\text { Ragu Dan Tidak } \\
\text { Ada Pendapat }\end{array}$ & & & \\
\hline
\end{tabular}

Berdasarkan tabel tersebut, dapat di simpulkan bahwa sebanyak 20 responden (100\%) setuju, ketika Pelajaran Agama Kristen dapat memberikan perubahan dalam pergaulan siswa. 
Tabel $4.24 \mathrm{~N}=20$

Dengan Pendidikan Agama Kristen Mudah Memahami Kebenaran Firman Tuhan

\begin{tabular}{|l|l|l|l|}
\hline \multicolumn{1}{|c|}{ Valid } & \multicolumn{1}{|c|}{$\begin{array}{c}\text { Jawaban/ } \\
\text { Frekwensi }\end{array}$} & \multicolumn{1}{|c|}{ Persentase } & Total \\
\hline \hline Setuju (S) & 20 orang & $\begin{array}{l}20: 20 \times 100= \\
100 \%\end{array}$ & \\
\hline Tidak Setuju (TS) & & & \\
\hline $\begin{array}{l}\text { Ragu Dan Tidak Ada } \\
\text { Pendapat }\end{array}$ & & & \\
\hline
\end{tabular}

Berdasarkan tabel tersebut dapat disimpulkan bahwa responden sebanyak 20 orang (100\%) setuju, ketika pelajaran Pendidikan Agama Kristen dapat mudah di pahami siswa melalui kebenaran firman Tuhan.

Tabel $4.25 \mathrm{~N}=20$

Pelajaran Pemdidikan Agama Kristen Dapat Membawa Saya Mengenal Yesus Secara Pribadi sebagai Tuhan dan Juru Selamat

\begin{tabular}{|l|l|l|l|}
\hline \multicolumn{1}{|c|}{ Valid } & $\begin{array}{c}\text { Jawaban/ } \\
\text { Frekwensi }\end{array}$ & Persentase & Total \\
\hline \hline Setuju (S) & 20 & $20: 20 \times 100=100 \%$ & \\
\hline Tidak Setuju (TS) & & & \\
\hline $\begin{array}{l}\text { Ragu Dan Tidak } \\
\text { Ada Pendapat }\end{array}$ & & & \\
\hline
\end{tabular}

Berdasarkan tabel sebanyak 20 orang responden (100\%) setuju ketika pelajaran Pendidikan Agama Kristen dapat mebawa siswa mengenal Yesus secara pribadi sebagai Tuhan dan Juru Selamat.

Tabel $4.26 \mathrm{~N}=20$

Guru Agama Kristen berbeda Dengan Guru mata Pelajaran Lainya

\begin{tabular}{|l|l|l|l|}
\hline \multicolumn{1}{|c|}{ Valid } & \multicolumn{1}{c|}{$\begin{array}{c}\text { Jawaban/ } \\
\text { Frekwensi }\end{array}$} & \multicolumn{1}{c|}{ Persentase } & Total \\
\hline \hline Setuju (S) & 20 & $20: 20 \times 100=100 \%$ & \\
\hline Tidak Setuju (TS) & & & \\
\hline $\begin{array}{l}\text { Ragu Dan Tidak Ada } \\
\text { Pendapat }\end{array}$ & & & \\
\hline
\end{tabular}

Berdasarkan tabel tersebut dapat di simpulkan bahwa responden sebanyak 20 orang $(100 \%)$ setuju, ketika mereka merasa ada perbedaan antara guru Pendidikan Agama Kristen dengan guru pembelajaran lainya. 
Tabel $4.27 \mathrm{~N}=20$

Saya Jadi Suka Membaca Alkitab Dari Pelajaran Agama Kristen Yang Saya Terimah Di Sekolah

\begin{tabular}{|l|l|l|l|}
\hline \multicolumn{1}{|c|}{ Valid } & \multicolumn{1}{c|}{$\begin{array}{c}\text { Jawaban/ } \\
\text { Frekwensi }\end{array}$} & Persentase & Total \\
\hline \hline Setuju (S) & 20 & $20: 20 \times 100=100 \%$ & \\
\hline Tidak Setuju (TS) & & & \\
\hline $\begin{array}{l}\text { Ragu Dan Tidak Ada } \\
\text { Pendapat }\end{array}$ & & & \\
\hline
\end{tabular}

Berdasarkan tabel tersebut dapat di simpulkan bahwa sebanyak 20 responden (100\%) setuju mereka menjadi suka membaca Alkitab dari Pelajaran Agama Kristen yang di terima di sekolah.

Tabel $4.28 \mathrm{~N}=20$

Pembelajaran PAK menggunakan pendekatan saintifik saya berani bersaksi tentang kebaikan Tuhan

\begin{tabular}{|l|l|l|l|}
\hline \multicolumn{1}{|c|}{ Valid } & $\begin{array}{c}\text { Jawaban/ } \\
\text { Frekwensi }\end{array}$ & Persentase & Total \\
\hline Setuju (S) & 20 & $20: 20 \times 100=100 \%$ & \\
\hline Tidak Setuju (TS) & & & \\
\hline $\begin{array}{l}\text { Ragu Dan Tidak Ada } \\
\text { Pendapat }\end{array}$ & & & \\
\hline
\end{tabular}

Berdasarkan tabel tersebut dapat di simpulkan bahwa sebanyak 20 responden (100\%) setuju, ketika pembelajaran dengan pendekatan saintifik dalam pembelajaran PAK membuat siswa berani bersaksi tentang kebaikan Tuhan.

Tabel $4.29 \mathrm{~N}=20$

Pembelajaran Pendidikan Agama Kristen menyakinkan Saya Bahwa Yesus Kristus Adalah Tuhan Dan Juru Selamat

\begin{tabular}{|l|l|l|l|}
\hline \multicolumn{1}{|c|}{ Valid } & $\begin{array}{c}\text { Jawaban/ } \\
\text { Frekwensi }\end{array}$ & Persentase & Total \\
\hline Setuju (S) & 20 & $20: 20 \times 100=100 \%$ & \\
\hline Tidak Setuju (TS) & & & \\
\hline $\begin{array}{l}\text { Ragu Dan Tidak } \\
\text { Ada Pendapat }\end{array}$ & & & \\
\hline
\end{tabular}


Berdasarkan tabel sebanyak 20 orang responden (100\%) setuju, melalui pembelajaran Pendidikan Agama Kristen menyakinkan bahwa yesus kristus adalah Tuhan dan juru selamat.

Tabel $4.30 \mathrm{~N}=20$

Implementasi Alkitab Dapat di Permudah Ketika Di ajarkan Melalui Pendidikan Agama Kristen

\begin{tabular}{|l|l|l|l|}
\hline \multicolumn{1}{|c|}{ Valid } & \multicolumn{1}{c|}{$\begin{array}{c}\text { Jawaban/ } \\
\text { Frekwensi }\end{array}$} & Persentase & Total \\
\hline \hline Setuju (S) & 20 orang & $20: 20 \times 100=100 \%$ & \\
\hline Tidak Setuju (TS) & & & \\
\hline $\begin{array}{l}\text { Ragu Dan Tidak } \\
\text { Ada Pendapat }\end{array}$ & & & \\
\hline
\end{tabular}

Berdasarkan tabel tersebut dapat di simpulkan bahwa sebanyak 20 responden (100\%) setuju, ketika mengimplementasi Alkitab/Firman Tuhan dapat di permudah melalui pembelajaran Pendidikan Agama Kristen.

\section{Pembahasan}

Berdasarkan penelitian lapangan yang di lakukan khususnya melalui penyataanpenyataan yang meliputi pembelajaran dengan pendekatan saintifik terhadap pelajaran Pendidikan Agama Kristen kelas XI Farmasi SMK Nusantara Palu, penulis menemukan fakta berdasarkan data tersebut bahwa sebagian besar dari para responden lebih banyak memilih sangat setuju, hal ini membuktikan bahwa para responden memahami dan menyadari pentingya model pendekatan pembelajaran saintifik, Pendekatan santifik dalam pembelajaran Agama Kristen berdasarkan penelitian siswa menjadi aktif dan kreatif dalam proses pembelajaran yang dapat diartikan sebagai "segala usaha atau proses belajar mengajar dalam rangka terciptanya proses belajar mengajar yang efektif dan efisien kelas XI farmasi di SMK nusantara palu.

\section{Kesimpulan}

Pendekatan saintifik adalah model pembelajaran yang menggunakan kaidah - kaidah keilmuan yang memuat serangkaian aktivitas pengumpulan data melalui observasi, menanya, eksperimen, mengolah informasi atau data kemudian mengkomunikasikan. Pembelajaran dengan menggunakan metode Pendekatan santifik dalam pembelajaran Agama Kristen siswa menjadi aktif dan menyenangkan dalam proses pembelajaran. Guru pendidikan agama kristen adalah seorang yang membantu peserta didik untuk 
berkembang agar dapat memasuki persekutuan iman dengan Tuhan Yesus Kristus, dan guru Pendidikan Agama Kristen menjadi termotivasi untuk kreatif. Sekolah atau lembaga pendidikan dapat mengembangkan model pembelajaran yang sesuai kurikulum 2013. Yesus adalah guru Agung yang pengajaran-Nnya luar biasa, Dia adalah Pendidik yang tiada taranya. Dengan adanya penerapan metode pendekatan saintifik sangat bermanfaat dalam proses pembelajaran Pendidikan Agama Kristen secara efektif di sekolah SMK Farmasi XI Nusantara palu.

\section{Referensi}

Ahmad rohani, Pengelolaan Pengajaran (Jakarta: PT Bumi Aksara, 2004)

Amir Hamzah, Etos Kerja Guru (Jakarta: Literasi Nusantara, 2019)

B.S Sidjabat, Mengajar Secara Profesional (Jakarta: BPK Gunung Mulia)

-_- Mengajara Secara Profesional (Jakarta: BPK Gunung Mulia)

Dept Pendidikan \& Kebudayaan, Guru Dan Dosen (Jakarta: Himpunan UU RI, 2009)

https://www.asikbelajar.com, 'Pengertian Proses Pembelajaran' (https:// www.asikbelajar.com, 2020)

https://www.kemdikbud.go.id, 'Paparan Wamendik' (Jakarta: https:// www.kemdikbud.go.id

Khanifatul, Pembelajaran Inovatif

Lembaga Alkitab Indonesia, 'Alkitab Terjemahan Baru' (Jakarta: Lembaga Alkitab Indonesia, 2017)

Muchlisin Riadi, 'Prinsip Dan Langkah Pendekatan Saintifik' (Jakarta: Kajian Pustaka.Com, 2019)

Paulus Lilik Kristianto, Prinsip Dan Praktik Pendidikan Agama Kristen (Yogyakarta: Andi, 2006)

Sumiyatiningsih, Dien, Mengajar Dengan Kreatif Dan Menarik (Yogyakarta: Andi, 1987)

Syah.Muhibin, Psikologi Pendidikan Dengan Pendekatan Baru (Bandung: Remaja Rosda Karya, 2008)

Tim Penyusun Kamus Besar Bahasa Indonesia, Kamus Besar Bahasa Indonesia (Jakarta: Balai Pustaka, 1995 